\title{
Estimation of Missed Statin Prescription Use in an Administrative Claims Dataset
}

Rolin L. Wade, RPh, MS; Jeetvan G. Patel, PhD; Jerrold W. Hill, PhD;

Ajita P. De, MA, MPhil, MS; and David J. Harrison, PhD

\begin{abstract}
BACKGROUND: Nonadherence to statin medications is associated with increased risk of cardiovascular disease and poses a challenge to lipid management in patients who are at risk for atherosclerotic cardiovascular disease. Numerous studies have examined statin adherence based on administrative claims data; however, these data may underestimate statin use in patients who participate in generic drug discount programs or who have alternative coverage.
\end{abstract}

OBJECTIVE: To estimate the proportion of patients with missing statin claims in a claims database and determine how missing claims affect commonly used utilization metrics.

METHODS: This retrospective cohort study used pharmacy data from the PharMetrics Plus $(\mathrm{P}+)$ claims dataset linked to the IMS Iongitudinal pharmacy point-of-sale prescription database (LRx) from January 1, 2012, through December 31, 2014. Eligible patients were represented in the P+ and LRx datasets, had $\geq 1$ claim for a statin (index claim) in either database, and had $\geq 24$ months of continuous enrollment in $P+$. Patients were linked between $\mathrm{P}+$ and LRx using a deterministic method. Duplicate claims between $L R x$ and $P+$ were removed to produce a new dataset comprised of $P+$ claims augmented with LRx claims. Statin use was then compared between $\mathrm{P}+$ and the augmented $\mathrm{P}+$ dataset. Utilization metrics that were evaluated included percentage of patients with $\geq 1$ missing statin claim over 12 months in $\mathrm{P}+$; the number of patients misclassified as new users in $\mathrm{P}+$; the number of patients misclassified as nonstatin users in $\mathrm{P}+$; the change in 12-month medication possession ratio (MPR) and proportion of days covered (PDC) in $\mathrm{P}+$; the comparison between $\mathrm{P}+$ and $\mathrm{LRx}$ of classifications of statin treatment patterns (statin intensity and patients with treatment modifications); and the payment status for missing statin claims.

RESULTS: Data from 965,785 patients with statin claims in $\mathrm{P}+$ were analyzed (mean age 56.6 years; $57 \%$ male). In $\mathrm{P}+, 20.1 \%$ had $\geq 1$ missing statin claim post-index; $13.7 \%$ were misclassified as nonstatin users; and $14.9 \%$ were misclassified as new statin users. MPR was higher in the augmented $\mathrm{P}+$ dataset versus the $\mathrm{P}+$ dataset alone for all patients $(79.4 \%$ vs. $76.7 \%, P<0.001)$ and new users $(61.4 \%$ vs. $58.7 \%, P<0.001)$. Similarly, mean $\mathrm{PDC}$ was higher in the $\mathrm{P}+$ dataset augmented with $\mathrm{LRx}$ versus the $\mathrm{P}+$ dataset alone for all patients $(76.0 \%$ vs. $74.0 \%, P<0.001)$ and new users (58.5\% vs. $56.5 \%, P<0.001)$. Most patients received moderate-intensity statins; few changes in dose, intensity, or discontinuation of statins were observed when the $\mathrm{P}+$ dataset was augmented. The most common reasons for missing data were payment by an alternate third-party program $(66.3 \%)$ and use of cash, coupon, or discount cards (18.7\%).

CONCLUSIONS: Augmenting commercial claims data with point-of-sale data provides a more accurate assessment of statin use than claims data alone.

J Manag Care Spec Pharm. 2017;23(9):936-42

Copyright $\odot 2017$, Academy of Managed Care Pharmacy. All rights reserved.

\section{What is already known about this subject}

Utilization metrics, including adherence to statin therapies, has traditionally been estimated by using health plan administrative claims databases.

Analyses may underestimate statin adherence and other utilization metrics in claims databases for patients who use alternative payment programs or who pay for their prescriptions with cash.

\section{What this study adds}

This analysis of statin claims in a commercial claims database augmented with point-of-sale pharmacy data revealed a significant proportion of patients with missing statin claims.

This study identified reasons for missing statin claims, which included filling statin prescriptions through drug discount programs and through cash payment.

This study quantified the underreporting of statin use in traditional health insurance claims databases.

$\mathrm{T}$ he American College of Cardiology/American Heart Association (ACC/AHA) 2013 cholesterol guideline recommends the use of statins for secondary prevention in adults with clinical atherosclerotic cardiovascular disease (ASCVD) and for primary prevention in certain subgroups (e.g., adults with very high low-density lipoprotein cholesterol [LDLC] levels, LDL-C $<190 \mathrm{mg} / \mathrm{dL}$ with diabetes mellitus, or an estimated 10 -year ASCVD risk of $7.5 \%$ or higher). ${ }^{1}$ Nonadherence to statins is a major challenge to optimal management of this patient population, with many studies reporting 1-year dropout rates of up to $48 \% .{ }^{2}$ In addition, studies have reported that up to one third of patients with a history of ASCVD do not initiate statin treatment. ${ }^{3}$ Statin nonadherence is associated with an increased risk of cardiovascular disease (risk estimates: 1.22-5.26) and mortality (risk estimates: 1.25-2.54). ${ }^{4}$

Most statin adherence studies use data from health plan administrative claims databases, which contain information on adjudicated prescriptions paid by health plans. A number of major pharmacy chains offer low-cost generic prescriptions, which include a number of generic statins that are widely available for approximately $\$ 4.00$ per month..$^{5}$ If patients take advantage of generic drug discount programs (GDDPs) and pay for these prescriptions outside of their insurance plans, these 
transactions may not be recorded in a typical claims dataset and may therefore lead to systematic underestimation of statin use in these databases. The use of GDDPs also affects the clinical management of patients who use them. For example, health plans may have utilization management programs in place that require members to have tried a certain number or type of statin before moving to a second-line therapy. If previous use is underestimated, patients may be denied access to therapies for which they are eligible, thus, delaying or withholding access to care. Statins are a class of medication where this effect may be common because of the availability of low-cost generics at many retail pharmacies.

Health plan pharmacy claims can be augmented with claims available in point-of-sale databases by linking claims across these sources to allow identification of prescription drug purchases made outside of a patient's insurance plan. The objective of this study was to estimate the proportion of patients with missing statin claims in an administrative health plan dataset and to determine how augmenting traditional health plan claims data with point-of-sale pharmacy data affects common measures of statin use.

\section{Methods}

\section{Data Sources}

Data for this study were obtained from 2 databases: (1) PharMetrics Plus (P+), ${ }^{6}$ a conventional, fully adjudicated, commercial health plan claims database, and (2) the IMS Patient Centric Pharmacy Claims database (longitudinal pharmacy database [LRx]), an open-source, point-of-sale prescription claims database that covers more than $88 \%$ of all retail, mail, and specialty pharmacy transactions in the United States. The aggregated $\mathrm{P}+$ database comprises adjudicated pharmacy and medical claims for more than 95 million unique enrollees across the United States since 2006. Enrollees with medical and pharmacy coverage in 2012-2014 represented approximately 40 million active lives annually. The P+ dataset has diverse representation of geography, employers, payers, providers, and therapy areas. The IMS LRx database captures information on adjudicated pharmacy transactions from retail, mail order, long-term care, and specialty pharmacies. IMS LRx has $88 \%$ coverage of the retail channel, $55 \%$ of standard mail service, and $40 \%-70 \%$ of specialty pharmacy volume.

The point-of-sale open-source pharmacy claims in LRx consist of dispensed prescriptions captured by the suppliers on a daily basis, and weekly data feeds are generated with an ability to provide insight within 10 days of the transaction.

\section{Study Design}

This was a retrospective cohort study to describe statin treatment patterns. The study period was from January 1, 2012, through December 31, 2014. Patient data in the P+ and LRx datasets were linked using a deterministic method for data linkage., ${ }^{7,8}$ The IMS-patented and proprietary Health Insurance Portability and Accountability Act (HIPAA)-compliant encryption algorithm was used on the source data to create a unique patient identification or token for each patient, ${ }^{9}$ which allowed for a deterministic patient-specific linkage between databases. The algorithm used data elements that included gender, date of birth, last name, first name, address, city, state, and ZIP code and has been previously described..$^{10}$ Both databases went through the IMS standard quality control and adjudication processes to ensure that the data transactions were considered final and that they could be used for research purposes. Statin claims in P+ were matched to LRx by encrypted patient ID, age, sex, National Drug Code number, and fill date $( \pm 3$ days between sources). Statin claims in LRx were added to statin claims in $\mathrm{P}+$; then, duplicate claims were removed to create the $\mathrm{P}+$ augmented by LRx dataset, allowing for a comparison of the $\mathrm{P}+$ dataset alone with the P+ augmented by LRx dataset.

\section{Patient and Cohort Identification}

Eligible patients were adults (aged $\geq 18$ years) represented in the P+ and LRx datasets, who had at least 1 claim for a statin (as a single ingredient dosage form, as a fixed-dose combination product, or as ezetimibe as a single ingredient) in either database and at least 24 months of continuous enrollment in P+ between January 1, 2012, and December 31, 2014. The index date was the day of each patient's first statin prescription in the respective datasets. Patients were assigned to 1 of 2 cohorts: patients with statin claims in $\mathrm{P}+$ during the study period (cohort A) and patients with no statin claims in $\mathrm{P}+$ but with statin claims in LRx (cohort B) during the study period.

\section{Study Outcomes}

The following 6 outcome measures were evaluated:

1. The percentage of patients with at least 1 missing statin claim in $P+$ during the 12-month post-index period. This was evaluated by identifying those patients with a higher post-index statin claim count in $\mathrm{P}+$ after the data were augmented with LRx.

2. The number of patients misclassified as new users using P+ data alone. New users in $\mathrm{P}+$ were classified as those with a 12-month washout period before the index date, while those misclassified as new users failed the washout when the P+ dataset was augmented with the LRx dataset.

3. The number of patients misclassified as nonstatin users using P+ data alone. These were the patients in cohort B with statin claims in LRx but no claims in P+.

4. Changes in 12-month medication possession ratio (MPR) and proportion of days covered (PDC), as well as discontinuation for all patients and for patients new to statin therapy. MPR was calculated as the sum of the days supply post-index divided by 365 days and multiplied by $100 \%$. PDC was calculated as the sum of unique nonoverlapping days supply post-index divided by 365 and multiplied by 100\%. Discontinuation 


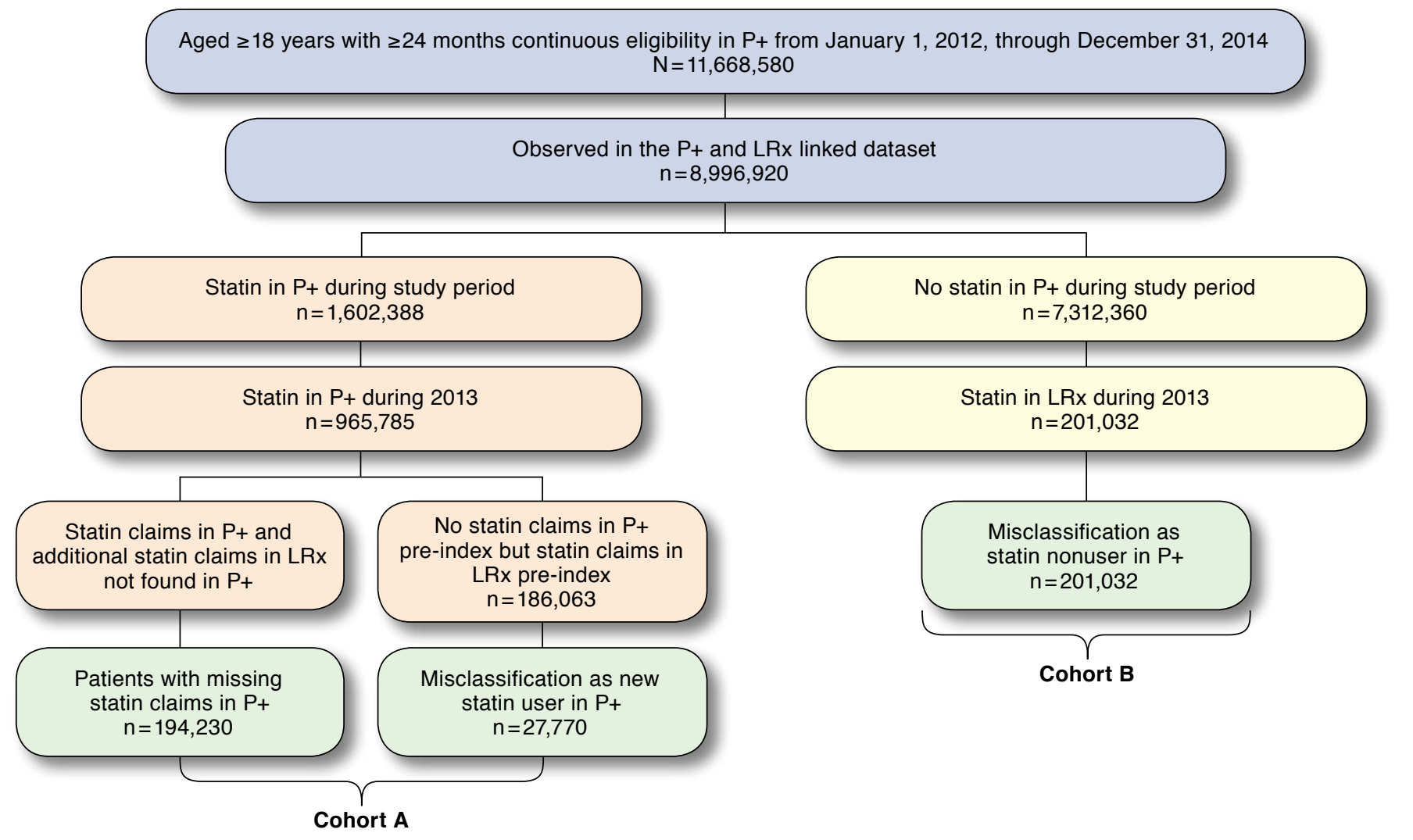

LRx = IMS longitudinal pharmacy point-of-sale prescription claims database; $P+=$ PharMetrics Plus claims database.

was defined by a 90-day gap in therapy, with a 60 -day gap used as a sensitivity analysis; patients with a claim following the 90- or 60-day gap in therapy were defined as restarts. New statin users were defined as patients who did not have a claim for a statin in either dataset during the 12-month pre-index period.

5. A comparison was made between the P+ dataset and the P+ augmented with LRx dataset regarding the classification of statin treatment patterns and modifications. Treatment modifications included drug switches and changes in statin intensity and dose (increase or decrease), measured as the difference between intensity or dose at index and the last intensity or dose received in the follow-up period. Criteria for classification of statin intensity are presented in Appendix A (available in online article). To allow comparisons in doses for patients using more than 1 statin post-index, all doses were converted to simvastatin-equivalent doses (see Appendix B for dose equivalents, available in online article). ${ }^{11,12}$ Use of combination therapies at index and switches from monotherapy to combination therapy post-index were analyzed.
6. The payment status (e.g., cash, Medicaid, and commercial) for missing statin claims. This measure included those that were added when $\mathrm{P}+$ was augmented with LRx. To understand reasons for missing data in $\mathrm{P}+$, we examined the claims in LRx that were missing in $\mathrm{P}+$ for cohort A. Payer type was examined to identify cash payments and other third-party payments arising from alternate benefits available to the patient. In missing claims with zero payment by third-party insurers, we analyzed the distribution of patient copayments to determine the proportion of payments that would be consistent with widely available low-cost generics.

\section{Statistical Considerations}

Descriptive statistics were generated for patient and treatment characteristics. A paired t-test or McNemars test was used to assess the difference between study measures in the P+ dataset and the P+ augmented with LRx dataset. All statistics used a 2-sided test with an alpha of 0.05 to determine significance. 
TABLE 1 Demographic Characteristics at Baseline

P+ Augmented with LRx $(\mathrm{N}=965,785)$

\begin{tabular}{|c|c|c|}
\hline & & \\
\hline Age, mean years (SD) & 56.7 & $(9.3)$ \\
\hline Sex, male, n (\%) & 563,206 & $(58.3)$ \\
\hline Geographic region, $\mathbf{n}$ & & \\
\hline Northeast & 291,107 & $(30.1)$ \\
\hline Midwest & 215,653 & $(22.3)$ \\
\hline South & 416,115 & $(43.1)$ \\
\hline West & 42,910 & (4.4) \\
\hline Payer type, n (\%) & & \\
\hline Commercial plan & 543,116 & $(56.2)$ \\
\hline Medicaid & 5,265 & $(0.5)$ \\
\hline Medicare MAPD & 20,982 & $(2.2)$ \\
\hline Self-insured & 395,744 & $(41.0)$ \\
\hline Unknown & 678 & $(0.1)$ \\
\hline
\end{tabular}

Plan type, n (\%)

\begin{tabular}{|c|cc}
\hline Consumer-directed health care product & $9,323 \quad(1.0)$ \\
\hline
\end{tabular}

\begin{tabular}{l|r}
\hline Health maintenance organization & $97,918 \quad(10.1)$ \\
\hline
\end{tabular}

\begin{tabular}{|c|c|}
\hline Indemnity plan & $27,091 \quad(2.8)$ \\
\hline
\end{tabular}

\begin{tabular}{l|rr}
\hline Point of service & $35,621 \quad(3.7)$ \\
\hline Preferred provider organization
\end{tabular}

\begin{tabular}{l|rr}
\hline Preferred provider organization & 794,371 & $(82.3)$ \\
\hline
\end{tabular}

\begin{tabular}{l|cc}
\hline Unknown & 1,461 & $(0.2)$ \\
\hline
\end{tabular}

LRX = IMS longitudinal pharmacy point-of-sale prescription claims database; MAPD $=$ Medicare Advantage Prescription Drug plan; $P+=$ PharMetrics Plus claims database; $S D=$ standard deviation

\section{Results}

\section{Patient Cohort}

A total of $8,996,920$ patients was included in the P+ and LRx linked dataset (Figure 1), of which 1,602,388 (13.0\%) had at least 1 statin fill. Of these, 965,785 (60.3\%) patients had a claim for a statin in the $\mathrm{P}+$ dataset; 186,063 patients were classified as new users; the mean age was 56.7 years; and $58.3 \%$ of patients were male (Table 1).

Among the patients with a statin claim in the $\mathrm{P}+$ dataset (cohort A), 194,230 of 965,785 patients (20.1\%) had at least 1 missing post-index statin claim identified using the augmented database, and 27,770 of the 186,063 patients classified as new users in $\mathrm{P}+(14.9 \%)$ were misclassified as new statin users (Figure 1). An additional 201,032 (13.7\%) patients only had a claim for a statin in LRx (cohort B) and would have been classified as nonusers based on the P+ dataset alone.

\section{MPR and PDC}

As expected, the missing claims in $\mathrm{P}+$ alone resulted in lower estimates of medication adherence compared with $\mathrm{P}+$ augmented with LRX. MPR and PDC were significantly higher in $\mathrm{P}+$ augmented with LRx compared with $\mathrm{P}+$ alone across all patients and for new statin users $(P<0.001$; Table 2$)$.

\section{Statin Treatment Patterns}

The proportion of patients using high-intensity statins was $22.2 \%$ for $\mathrm{P}+$ alone and $22.4 \%$ for $\mathrm{P}+$ augmented with LRx $(P=0.009)$. Similarly, the proportion of patients with a dose change was significantly higher in the augmented dataset (dose increase $8.2 \%$ vs $7.7 \%, P<0.001$; dose decrease $4.1 \%$ vs. $3.6 \%, P<0.001$ ). Discontinuation based on a 90-day gap was lower when $\mathrm{P}+$ was augmented with LRx data (26.4\% vs. $28.6 \%, P<0.001)$, and reinitiating rates were higher $(5.1 \%$ vs. $14.1 \%, P<0.001)$. Similar results were seen when a 60 -day gap was used.

\section{Reasons for Missing Data}

Cash, vouchers, and coupons were associated with the transactions for $18.7 \%$ of missing claims. Government programs (i.e., Medicaid, workers compensation, and other assistance programs) were associated with $7.9 \%$ of missing claims (Table 3 ). The remaining $73.4 \%$ of missing claims were associated with patients with a health plan identified as a health maintenance organization (9.5\%), preferred provider organization (13.3\%), employer-sponsored/pharmacy benefit manager [PBM]-administered (10.7\%), or with an undesignated health plan type (39.9\%). Patients paid the full amount for $20 \%$ of the missing claims; of these, $60 \%$ of prescriptions cost $\leq \$ 10$, which may reflect in part the use of GDDPs.

\section{Discussion}

To our knowledge, this is the first published study to date to quantify the proportion of missing statin claims data in a typical claims dataset. Our analysis found that $20.1 \%$ of statin users had at least 1 missing claim during the first year following the index claim. Additionally, 13.7\% of patients were misclassified as nonstatin users, and $14.9 \%$ were misclassified as new statin users. These results demonstrate that the degree of missing statin data in a standard claims database is due, in part, to the use of GDDPs and other third-party payers.

Missing claims can also affect measures of statin treatment patterns such as dose changes, moving from monotherapy to combination therapy, switches to other statin therapies, and persistence with therapy. In general, missing data are associated with a lower likelihood of observing treatment changes in $\mathrm{P}+$ over time compared with $\mathrm{P}+$ augmented (treatment discontinuation is an exception where fewer data should show higher discontinuation). While many of the results demonstrated statistical significance, it may be argued that the clinical significance of the differences was nominal at the population level. Although true, a large proportion of patient records were affected, which may have an important effect, since utilization management is directed toward this population by health plans, PBMs, and provider groups.

GDDPs have been hailed as low-cost alternatives to regular prescription programs administered by health care plans and insurers, offering low costs for commonly used generic drugs 


\begin{tabular}{|c|c|c|c|}
\hline & P+ Only & $\begin{array}{c}\text { P+ Augmented } \\
\text { with LRx }\end{array}$ & $P$ Value \\
\hline \multicolumn{4}{|l|}{ Mean MPR \% (SD) } \\
\hline All patients $(\mathrm{N}=965,785)$ & $76.7 \quad(27.1)$ & $79.4(26.2)$ & $<0.001$ \\
\hline $\begin{array}{l}\text { Patients new to statins } \\
(\mathrm{n}=186,063)\end{array}$ & $58.7(33.0)$ & $61.4(33.2)$ & $<0.001$ \\
\hline \multicolumn{4}{|l|}{ Mean PDC \% (SD) } \\
\hline All patients $(\mathrm{N}=965,785)$ & $74.0(26.0)$ & $76.0(25.2)$ & $<0.001$ \\
\hline $\begin{array}{l}\text { Patients new to statins } \\
(\mathrm{n}=186,063)\end{array}$ & 56.5 (31.6) & $58.5(31.6)$ & $<0.001$ \\
\hline \multicolumn{4}{|c|}{$\begin{array}{l}\text { aNew to statins using a 12-month washout and the P+ augmented with LRx dato } \\
\text { LRx = IMS longitudinal pharmacy point-of-sale prescription claims database; } \\
\text { MPR = medication possession ratio; } P+=\text { PharMetrics Plus claims database; } \\
P D C=\text { proportion of days covered; } S D=\text { standard deviation. }\end{array}$} \\
\hline
\end{tabular}

without the inconvenience of filing a claim. ${ }^{13}$ These programs are frequently used by elderly and uninsured patients. ${ }^{13}$ GDDPs vary in the list of generic drugs covered, days supply, enrollment requirements, and cost per prescription. ${ }^{14}$ Although most generic drugs are covered under GDDPs, a recent study noted that coverage was higher for some indications (e.g., diabetes and hypertension) than others (mental disorders, arthritis, and pulmonary/respiratory conditions)..$^{15}$ The use of GDDPs has increased from $3.6 \%$ of patients receiving any prescription drugs in 2007 (when the first GDDP was established) to 23.1\% in 2010. ${ }^{16}$ Use of GDDPs can have a significant effect on health care costs. It has been estimated that if every patient used a $\$ 4.00$ GDDP in 2007 , the total savings would have been $\$ 5.78$ billion, including $\$ 3.23$ billion saved on patient out-of-pocket costs and $\$ 1.07$ billion of savings to Medicare. ${ }^{17}$ Reduced outof-pocket costs under GDDPs may also increase medication compliance if prescription copayments under the patient's insurance are a financial burden, which would increase the likelihood of nonadherence.

While the use of GDDPs offer cost savings to patients, an unintentional consequence may be less accuracy in measures used to monitor quality of care, and the consequences for health care plans rated on these measures..$^{5}$ This consequence is demonstrated in this study by the lower measures of medication compliance as measured by MPR and PDC in P+ versus P+ augmented by LRx claims. Similarly, the assessment of therapy-related adverse events may be understated in studies using claims data. Health plans are rated on measures of quality, using claims data in the Medicare stars ratings program, which potential health plan enrollees use to choose health plans.

Understating quality of care for a health plan because of missing claims data for measures such as medication compliance has 2 important consequences. First, the health plan is possibly placed at a competitive disadvantage by understating its quality (e.g., by reporting lower compliance in $\mathrm{P}+$ data

\section{TABLE 3 Reasons for Missing Claims}

\begin{tabular}{l|c}
\hline Reasons & \multicolumn{2}{|c}{ Number of Claims (\%)a } \\
\hline Cash/coupon/discount card & $72,447 \quad(18.7)$ \\
\hline Government programs & 30,606 \\
\hline Other third-party payers \\
\hline Health maintenance organization & 36,697 \\
\hline Preferred provider organization & $51,426 \quad(13.5)$ \\
\hline Employer-sponsored & $41,358 \quad(10.7)$ \\
\hline Undesignated plan type & $154,227 \quad(39.9)$ \\
\hline aA total of 386,761 claims were missing from the unaugmented P+ data. \\
P+=PharMetrics Plus claims database.
\end{tabular}

compared with compliance in the more complete $\mathrm{P}+$ augmented by LRx data found in this study). Second, the health plan may devote excessive resources to improve a quality of care problem that is overstated based on incomplete data. This may be done at the expense of addressing more pressing quality of care issues that would be identified with more complete claims data. Incomplete claims data will also overstate quality on standard quality of care measures such as polypharmacy (fewer drugs identified for evaluation of polypharmacy risk, understating risk) and adverse drug interactions (fewer adverse drug interventions identified, understating risk). As health care data systems become more integrated, rating systems based on clinical measures such as LDL-C level may become more feasible.

Claims data are used to evaluate and manage the quality of health care systems, ${ }^{5}$ and these processes could be compromised with incomplete or inaccurate datasets. Most prescriptions administered by health care plans are managed by PBMs. In addition to making formulary decisions and adjudicating claims, PBMs monitor drug use, which can assist in the implementation of disease management programs. Their data are used in comparative effectiveness studies to define treatment exposures analyzed, control variables on medication use and measures of patient comorbidities, and to examine incidence and prevalence data in large patient populations. Missing data from the administrative claims databases would therefore compromise these study measures. ${ }^{18}$

Two recent studies examining the effect of the 2013 ACC/ AHA Guideline on the Treatment of Blood Cholesterol reported on statin use in patients with ASCVD. Both studies reported some improvement in treatment patterns following the 2013 guideline, yet significant gaps were identified. It is possible that the treatment pattern estimates before and after the guideline were affected by missing data, since both studies used traditional health plan claims. ${ }^{19,20}$

While there were differences between the $\mathrm{P}+$ and the $\mathrm{P}+$ augmented datasets in estimates for statin treatment patterns, the patterns were similar in both data sources. Regardless of data source, most patients received moderate-intensity statins (Table 4). Few patients had a dose increase or decrease 


\begin{tabular}{|c|c|c|c|}
\hline $\begin{array}{l}\text { Proportion of Patients, } \\
\text { n (\%) }\end{array}$ & $\begin{array}{c}\mathrm{P}+\text { Only } \\
(\mathrm{N}=965,785)\end{array}$ & $\begin{array}{c}\mathrm{P}+\text { Augmented } \\
\text { with LRx } \\
(\mathrm{N}=965,785)\end{array}$ & $P$ Value \\
\hline $\begin{array}{l}\text { Low-intensity statin } \\
\text { (at index) }\end{array}$ & $118,037 \quad(12.2)$ & $117,540 \quad(12.2)$ & 0.275 \\
\hline $\begin{array}{l}\text { Moderate-intensity } \\
\text { statin (at index) }\end{array}$ & $602,158 \quad(62.3)$ & $601,474 \quad(62.3)$ & 0.310 \\
\hline $\begin{array}{l}\text { High-intensity statin } \\
\text { (at index) }\end{array}$ & $233,622 \quad(24.2)$ & $235,170 \quad(24.4)$ & 0.009 \\
\hline With dose increase & $74,058 \quad(7.7)$ & 78,903 & $<0.001$ \\
\hline With dose decrease & 35,130 & 39,597 & $<0.001$ \\
\hline With intensity escalation & 41,837 & 44,317 & $<0.001$ \\
\hline Low to moderate intensity & 14,142 & 14,845 & $<0.001$ \\
\hline Moderate to high intensity & 25,727 & 27,348 & $<0.001$ \\
\hline Low to high intensity & $1,968 \quad(0.2)$ & 2,124 & 0.015 \\
\hline With intensity reduction & 19,185 & 21,360 & $<0.001$ \\
\hline Moderate to low intensity & $7,295 \quad(0.8)$ & 8,042 & $<0.001$ \\
\hline $\begin{array}{l}\text { High to moderate } \\
\text { intensity }\end{array}$ & $10,852 \quad(1.1)$ & 12,133 & $<0.001$ \\
\hline High to low intensity & $1,038 \quad(0.1)$ & $1,185 \quad(0.1)$ & 0.002 \\
\hline Started on monotherapy & $926,716 \quad(96.0)$ & $924,157 \quad(95.7)$ & $<0.001$ \\
\hline $\begin{array}{l}\text { Augmented to } \\
\text { combination therapy }\end{array}$ & $72,885 \quad(7.9)$ & $80,281 \quad(8.7)$ & $<0.001$ \\
\hline $\begin{array}{l}\text { Started on combination } \\
\text { therapy }\end{array}$ & $39,069 \quad(4.0)$ & $41,628 \quad(4.3)$ & $<0.001$ \\
\hline $\begin{array}{l}\text { Augmented from } \\
\text { combination therapy }\end{array}$ & $4,620 \quad(11.8)$ & $5,583 \quad(13.4)$ & $<0.001$ \\
\hline $\begin{array}{l}\text { Discontinued } \\
(\geq 90 \text {-day gap) }\end{array}$ & $276,021 \quad(28.6)$ & $254,460 \quad(26.3)$ & $<0.001$ \\
\hline $\begin{array}{l}\text { Reinitiated after } \geq 90 \text {-day } \\
\text { gap }\end{array}$ & $38,786 \quad(14.1)$ & $38,402 \quad(15.1)$ & $<0.001$ \\
\hline $\begin{array}{l}\text { Discontinued } \\
(\geq 60 \text {-day gap) }\end{array}$ & $351,184 \quad(36.4)$ & $326,533 \quad(33.8)$ & $<0.001$ \\
\hline $\begin{array}{l}\text { Reinitiated after } \geq 60 \text {-day } \\
\text { gap }\end{array}$ & $194,032 \quad(55.3)$ & $183,318 \quad(56.1)$ & $<0.001$ \\
\hline \multicolumn{4}{|c|}{$\begin{array}{l}\text { Note: Because of the unavailability of published statin dose equivalents for } \\
\text { ezetimibe, dose intensity was unavailable for approximately } 1.2 \% \text { of patients on } \\
\text { ezetimibe monotherapy at index. } \\
\text { LRx=IMS longitudinal pharmacy point-of-sale prescription claims database; } \\
P+=\text { PharMetrics Plus claims database. }\end{array}$} \\
\hline
\end{tabular}

or change in dose intensity. The majority of patients were on statin monotherapy, and few augmented to combination therapy. Two definitions of discontinuation were assessed: a small proportion of patients reinitiated statin therapy under the definition using a 90-day gap, but a large proportion reinitiated under the definition using a 60-day gap.

\section{Limitations}

The administrative data used for this study (traditional health insurance claims data and point-of-sale prescription drug data) were generated from financial transactions for services and drugs received by patients. As such, data reporting from these sources on clinical measures such as patient diagnoses may not be consistent with the complete clinical assessment of health care providers. Administrative health care transactions data do not capture the level of detail documented in a patient's medical record. Outcome measures such as medical compliance measured by days of medication received from prescription fills assume that the patient uses the available supply from prescription fills. Health insurance claims data may incompletely document the use of health care services and drugs-as this study proposes to document. While the source data for this study, P+ and LRx, have extensive geographic coverage and cover a large percentage of the U.S. insured population, they do not represent a random sample of the U.S. population or the population treated with lipid-lowering therapies.

In addition, it is estimated that the linking procedure used to augment the $\mathrm{P}+$ data with the LRx data can have a false positive rate of up to $1 \%-2 \%$ and a false negative rate of approximately $3.5 \%$, so the estimates of missing data reported here may be slightly different than the true variation.

Finally, this study was conducted from 2012 to 2014; this timeline overlaps with the release of the 2013 ACC/AHA blood cholesterol guideline. While it is unclear what effect, if any, the revised guideline has had on statin prescribing patterns and how that may have affected our results, it is worth noting that our study covers the period before and after the guideline release.

\section{Conclusions}

In our analysis, prescription claims for a large proportion of statin users in a commercial claims database were missing. These missing claims have the potential to skew utilization analyses and quality management programs by health plans and PBMs. Specifically, measures of quality of care used to rate health plans, such as medication compliance, and health risks, such as polypharmacy, will be understated with missing claims data. Errors in quality of care measures can therefore affect a health plan's competitive position and its decisions on devoting resources to improve quality of care. Similarly, efforts by PBMs to use pharmacy claims to inform disease management and/or utilization management programs will be affected adversely by missing claims data. This study demonstrates the value of augmenting traditional health plan pharmacy claims data with open-source pharmacy fill data to more accurately measure medication use.

\section{Authors}

ROLIN L. WADE, RPh, MS; JERROLD W. HILL, PhD; and AJITA P. DE, MA, MPhil, MS, QuintilesIMS, Plymouth Meeting, Pennsylvania. JEETVAN G. PATEL, PhD, and DAVID J. HARRISON, PhD, Amgen, Thousand Oaks, California.

AUTHOR CORRESPONDENCE: Rolin L. Wade, RPh, MS, QuintilesIMS, 1 IMS Dr., Plymouth Meeting, PA 19462.

Tel.: 908.236.8972; E-mail: Rolin.Wade@quintilesims.com. 


\section{DISCLOSURES}

This study was funded by Amgen, which contributed to data interpretation and manuscript preparation. Wade, Hill, and De are employees of QuintilesIMS, which received funding from Amgen for work on this study. Patel and Harrison are employees of Amgen and own Amgen stock/stock options.

Study concept and design were contributed by Wade, Hill, Patel, and Harrison. De took the lead in data collection, along with the other authors, and all authors contributed to data analysis. The manuscript was written and revised by all the authors.

\section{ACKNOWLEDGMENTS}

Xinyan $\mathrm{Yu}$, QuintilesIMS, provided programming assistance. Annalise M. Nawrocki, PhD, Amgen, and Julia R. Gage, PhD, Amgen, provided medical writing support.

\section{REFERENCES}

1. Stone NJ, Robinson JG, Lichtenstein AH, et al. 2013 ACC/AHA guideline on the treatment of blood cholesterol to reduce atherosclerotic cardiovascular risk in adults: a report of the American College of Cardiology/ American Heart Association Task Force on Practice Guidelines. Circulation. 2014;129(25 Suppl 2):S1-45.

2. McGinnis B, Olson KL, Magid D, et al. Factors related to adherence to statin therapy. Ann Pharmacother. 2007;41(11):1805-11.

3. Maningat P, Gordon BR, Breslow JL. How do we improve patient compliance and adherence to long-term statin therapy? Curr Atheroscler Rep. 2013;15(1):291

4. De Vera MA, Bhole V, Burns LC, Lacaille D. Impact of statin adherence on cardiovascular disease and mortality outcomes: a systematic review. Br J Clin Pharmacol. 2014;78(4):684-98

5. Choudhry NK, Shrank WH. Four-dollar generics-increased accessibility, impaired quality assurance. N Engl J Med. 2010;363(20):1885-87.

6. Huse DM, Russo PA, Vasey J. Expanding the evidence base in outcomes research: linking electronic medical records and claims data. ISPOR Connections. 2013;19(3):5-7. Available at: https://www.ispor.org/news/articles/ISPORConnections_Vol19No3_MayJune2013.pdf. Accessed July 20, 2017

7. Ober NS, Grubmuller J, Farrell M, et al. System and method for generating de-identified health care data. U.S. Patent 6,732,113. May 4, 2004 Available at: http://patents.com/us-6732113.html. Accessed July 20, 2017.

8. Zubeldia K, Romney, GW. Anonymously linking a plurality of data records. U.S. Patent 6,397,224. May 28, 2002. Available at: http://www.patents.com/us-6397224.html. Accessed July 20, 2017.
9. Fox KM, Wang L, Gandra SR, Quek RG, Li L, Baser O. Clinical and economic burden associated with cardiovascular events among patients with hyperlipidemia: a retrospective cohort study. BMC Cardiovasc Disord. 2016:16:13.

10. Cepeda MS, Fife D, Denarie M, Bradford D, Roy S, Yuan Y. Quantification of missing prescriptions in commercial claims databases: results of a cohort study. Pharmacoepidemiol Drug Saf. 2017;26(4):386-92.

11. Kelley C, Helfand M, Good C, Ganz M. Drug class review. Hydroxymethylglutaryl-coenzyme A reductase inhibitors (statins) VHA Pharmacy Benefits Management Strategic Healthcare Group and the Medical Advisory Panel. December 2002. Available at: http://www.pbm.va.gov/clinicalguidance/drugclassreviews/ HMGCoAReductaseInhibitorsStatinsDrugClassReviewandAppendices.pdf. Accessed July 21, 2017.

12. VA Pharmacy Benefits Management Services. Pitavastatin (Livalo) national drug monograph. January 2012. Available at: https://www.pbm. va.gov/clinicalguidance/drugmonographs.asp. Accessed July 21, 2017.

13. Sifferlin A. Generic drug discount programs work-for everyone. Time September 22, 2014. Available at: http://time.com/3414980/generic-drugdiscount-programs/. Accessed July 21, 2017.

14. Patel HK, Dwibedi N, Omojasola A, Sansgiry SS. Impact of generic drug discount programs on managed care organizations. Am J Pharm Benefits. 2011;3(1):45-53

15. Patel HK, Akinwunmi PO, Sansgiry SS. Extent of drug coverage across generic drug discount programs offered by community pharmacies: a look at five chronic conditions. Inov Pharm. 2012;3(2):Article 81

16. Hong S, Tak SH. Uptake of generic drug discount program among vulnerable populations. JAMA Intern Med. 2014;174(11):1858-60.

17. Zhang Y, Zhou L, Gellad WF. Potential savings from greater use of $\$ 4$ generic drugs. Arch Intern Med. 2011;171(5):468-69.

18. Zhu VJ, Belsito A, Tu W, Overhage JM. Data for drugs available through low-cost prescription drug programs are available through pharmacy benefit manager and claims data. BMC Clin Pharmacol. 2012;12:12.

19. Tran J, Kao T, Caglar T, et al. Impact of the 2013 cholesterol guideline on patterns of lipid-lowering treatment in patients with atherosclerotic cardiovascular disease or diabetes after 1 year. J Manag Care Spec Pharm. 2016;22(8):901-08. Available at: http://www.jmcp.org/doi/10.18553/ jmcp.2016.22.8.901.

20. Bellows B, Olsen C, Voelker J, Wander C. Antihyperlipidemic medication treatment patterns and statin adherence among patients with ASCVD in a managed care plan after release of the 2013 ACC/AHA guideline on the treatment of blood cholesterol. J Manag Care Spec Pharm. 2016;22(8):892-900. Available at: http://www.jmcp.org/doi/10.18553/jmcp.2016.22.8.892. 


\begin{tabular}{l|c|c|c}
\multicolumn{3}{c}{ APPENDIX A Statin Intensity Assignment } \\
\cline { 2 - 4 } & \multicolumn{3}{|c}{ Daily Dose } \\
\cline { 2 - 4 } $\begin{array}{l}\text { Statin } \\
\text { Therapy }\end{array}$ & $\begin{array}{c}\text { Low } \\
\text { Intensity }\end{array}$ & $\begin{array}{c}\text { Moderate } \\
\text { Intensity }\end{array}$ & $\begin{array}{c}\text { High } \\
\text { Intensity }\end{array}$ \\
\hline Atorvastatin & $<10 \mathrm{mg} /$ day & 10 to $<40 \mathrm{mg} /$ day & $\geq 40 \mathrm{mg} /$ day \\
\hline Fluvastatin & $<80 \mathrm{mg} /$ day & $80 \mathrm{mg} /$ day & N/A \\
\hline ovastatin & $<40 \mathrm{mg} /$ day & $\geq 40 \mathrm{mg} /$ day & N/A \\
\hline itavastatin & $<2 \mathrm{mg} /$ day & $\geq 2 \mathrm{mg} /$ day & N/A \\
\hline Pravastatin & $<40 \mathrm{mg} /$ day & $\geq 40 \mathrm{mg} /$ day & N/A \\
\hline Rosuvastatin & $<5 \mathrm{mg} /$ day & 5 to $<20 \mathrm{mg} /$ day & $\geq 20 \mathrm{mg} /$ day \\
\hline Simvastatin & $<20 \mathrm{mg} /$ day & 20 to $<80 \mathrm{mg} /$ day & $\geq 80 \mathrm{mg} /$ day \\
\hline N/A =not applicable.
\end{tabular}

\section{APPENDIX B}

Statin Dose Equivalents

Approximate Equivalent Daily Doses of Statins: LDL-Lowering Data from Clinical Trials

\begin{tabular}{|c|c|c|c|c|c|c|}
\hline Lovastatin & Simvastatin & Fluvastatin & Pravastatin & Atorvastatin & Rosuvastatin & Pitavastatin \\
\hline $10 \mathrm{mg}$ & & $20 \mathrm{mg}$ & $10 \mathrm{mg}$ & & & \\
\hline $20 \mathrm{mg}$ & $10 \mathrm{mg}$ & $40 \mathrm{mg}$ & $20 \mathrm{mg}$ & & & $1 \mathrm{mg}$ \\
\hline $40 \mathrm{mg}$ & $20 \mathrm{mg}$ & $80 \mathrm{mg}$ & $40 \mathrm{mg}$ & $10 \mathrm{mg}$ & & $2 \mathrm{mg}$ \\
\hline \multicolumn{7}{|l|}{$60 \mathrm{mg}$} \\
\hline \multirow[t]{4}{*}{$80 \mathrm{mg}$} & $40 \mathrm{mg}$ & & $80 \mathrm{mg}$ & $20 \mathrm{mg}$ & $5 \mathrm{mg}$ & $4 \mathrm{mg}$ \\
\hline & $80 \mathrm{mg}$ & & & $40 \mathrm{mg}$ & $10 \mathrm{mg}$ & \\
\hline & & & & $80 \mathrm{mg}$ & $20 \mathrm{mg}$ & \\
\hline & & & & & $40 \mathrm{mg}$ & \\
\hline
\end{tabular}

